\title{
Free conjunctival grafts in the repair of leaking filtering blebs
}

\author{
Retalhos livres de conjuntiva no reparodebolhas filtrantes com vazamento
}

\author{
Renato C. Costa ${ }^{1}$ \\ Zélia Maria da Silva Corrêa ${ }^{2}$ \\ Richard P. Wilson ${ }^{3}$ \\ Italo Mundialino Marcon ${ }^{4}$ \\ Fabiana Buffé ${ }^{5}$
}

\begin{tabular}{|l|}
\hline ABSTRACT \\
\hline Purpose: To evaluate the effectiveness of free conjunctival grafting for \\
leaking conjunctival blebs following trabeculectomy. Methods: Retros- \\
pective study of seven patients with leaking conjunctival blebs that were \\
repaired by free conjunctival grafting. The effectiveness of this procedure \\
in stopping the bleb leak, maintaining satisfactory intraocular pressure \\
(IOP), maintaining satisfactory anterior chamber depth, and preserving \\
vision was evaluated. Results: Free conjunctival grafting appeared to \\
have stopped the bleb leak in 6 patients ( $85.7 \%)$, maintained satisfactory \\
IOP in 5 patients (71.4\%), maintained satisfactory anterior chamber depth \\
in all patients, and preserved pretreatment vision in 3 patients. Conclusions: \\
Free conjunctival grafting appears to be an effective method to treat \\
leaking blebs, without loss of IOP control.
\end{tabular}

Keywords: Glaucoma; Trabeculectomy; Conjunctiva/surgery; conjunctiva/transplantation

\section{INTRODUCTION}

Guarded filtrating surgery is a common procedure to control intraocular pressure (IOP) in patients with glaucoma when medical or laser therapy are not effective. The growing popularity of antimetabolites such as 5-fluoracil (5-FU) and mitomycin-C (MMC) during or immediately after the filtrating procedures has improved the success of surgery but the occurrence of thin, ischemic blebs after trabeculectomy has also become common ${ }^{(1-3)}$. It is known that 5-fluorouracil and MMC inhibit fibroblast proliferation that result in thinner, more fragile blebs ${ }^{(4)}$. Bleb leaks can occur months to years after filtrating surgery ${ }^{(4-6)}$, and ischemic, thin-walled blebs are more susceptible to leakage than thicker blebs ${ }^{(1,2,6-7)}$. Chronic bleb leaks may predispose the eye to endophthalmitis, hypotony, flat anterior chamber, peripheral anterior synechia, corneal decompensation, macular edema, blebitis and choroidal detachment. ${ }^{(4,8)}$ Conservative treatment alternatives include patching, short course of antiobiotics, aqueous suppresants ${ }^{(9)}$, therapeutic contact lens ${ }^{(10)}$, collagen shield, and tissue adhesives. ${ }^{(1)}$ Surgical alternatives include external conjunctival cryopexy, thermal coagulation by cautery or argon laser ${ }^{(12)}$ or continuous-wave neodymium: yttrium-aluminum-garnet $(\mathrm{Nd}: \mathrm{YAG})^{(13)}$, direct suturing of the conjuntival hole ${ }^{(14)}$, patching with corneal or scleral $\operatorname{graft}^{(8,15)}$, autologous blood patch ${ }^{(16)}$, pediculated and free conjunctival grafts ${ }^{(4,8,14)}$. In this study, free conjunctival grafts were used as a surgical alternative in 7 patients who presented with bleb leaks after trabeculectomy. The purpose of this report is to evaluate the efficacy of free conjunctival grafts in the treatment of bleb leaks following trabeculectomy.

\section{METHODS}

Our study group consisted of 7 patients ( 5 women, 2 men) who had 
undergone previous glaucoma surgery and presented with postoperative bleb leakage (i.e., Seidel positive). Six patients had been treated with adjunctive antimetabolite either intraoperatively ( 3 cases with MMC) or immediately postoperative in subconjuntival injections for 5 days ( 3 cases with $5-\mathrm{FU}$ ). Only one patient had not received this type of medication. One of the authors (RPW) performed all surgeries to repair the bleb leaks. All surgical procedures were performed under retrobulbar anesthesia. The superior conjunctival area to be grafted was measured with a caliper. The bleb extent was measured by length, width, and height. The inferior conjunctiva was ballooned up using a subconjunctival injection of balanced salt solution ( $\mathrm{BSS}^{\mathrm{TM}}$ ). The inferior conjunctiva was marked 1-3 mm wider than the area to be grafted depending upon bleb height. Six patients had grafts from the same eye and one patient from the fellow, poorer-seeing eye. The inferior conjunctival area was dissected using Westcott scissors. Conjunctiva plus a thin layer of Tennon's capsule was taken for donor tissue. The bleb was circumcised down to sclera with a 67 Beaver blade. The graft was sutured over this area using 10-0 nylon sutures in a running fashion. The suture was tied at each corner of the graft. At the end of the procedure, subconjunctival antibiotic (gentamicin-20 mg) was injected. Antibiotic ointment was applied and the eye was patched and shielded. Surgical results were classified as complete success (no bleb leak after one week posoperatively), partial success (a slight bleb after one week but none after one month postoperatively), and failure (a bleb leak that persisted for more than one month postoperatively).

Case description along with descriptive statistics such as mean, standard deviation and percentages were calculated with SPSS ${ }^{\circledR}$ (Statistical Package for the Social Sciences), version 6.0 for Windows.

\section{CASE SUMMARIES}

\section{Case 1}

A 55-year-old woman with primary open angle glaucoma (POAG) presented with a bleb leak 33 months after trabeculectomy with MMC in the left eye (OS). At examination, she had a deep anterior chamber (AC), IOP of $7 \mathrm{mmHg}$ and best corrected visual acuity of $20 / 25^{(-2)}$. Conjunctival patch grafting was performed. On postoperative day 1 , the bleb was still Seidel positive. However, on 2 week follow-up visit, the bleb was Seidel negative and the conjunctival graft appeared secured and well healed. The patient has been followed for 8 weeks, the bleb remained Seidel negative with an IOP of $9 \mathrm{mmHg}$.

\section{Case 2}

A 78-year-old woman with POAG presented with a bleb leak 6 years and 5 months after trabeculectomy with 5-FU in the right eye (OD). Autologous blood injection was performed in attempt to stop the bleb leak but was unsuccessful. One month after this procedure, it was decided to try a free conjunctival patch graft. At examination, she had a deep AC, an IOP of $5 \mathrm{mmHg}$, and a best corrected visual acuity of $20 / 40^{(-2)}$. Conjunctival patch grafting was performed. On postoperative day 1 , the bleb was Seidel negative. However on 1-week follow-up, the bleb was Seidel positive and from two weeks postoperatively until now it has been Seidel negative with an IOP of $7 \mathrm{mmHg}$.

\section{Case 3}

A 34-year-old man with juvenile glaucoma presented with a bleb leak 3 years and 4 months after trabeculectomy with MMC (OS). The two autologous blood injections performed were unsuccessful. Ten months after the last blood injection, it was decided to proceed with a free conjunctival patch graft. At preoperative examination, he had a deep AC, an IOP of $2 \mathrm{mmHg}$, and a best corrected visual acuity of $20 / 80^{(-2)}$. Conjunctival patch grafting was performed. On postoperative day 1, the bleb was Seidel negative. However, on 1-week followup, the bleb was Seidel positive and has remained this way as well as the IOP of $2 \mathrm{mmHg}$ until the last follow-up visit 22 weeks after surgery.

\section{Case 4}

A 70-year-old man with primary open angle glaucoma (POAG) presented with a bleb leak 6 years and 2 months after trabeculectomy with 5-FU in right eye. An unsuccessful autologous blood injection was performed. Two months after autologous blood injection, it was decided to proceed with free conjunctival patch graft. At examination, he had deep anterior chamber (AC), an IOP of $10 \mathrm{mmHg}$ and best corrected visual acuity of $20 / 30^{(-2)}$. Conjunctival patch grafting was performed. On postoperative day 1 , the filtering bleb was Seidel negative. The patient continued to do well as it is shown in figure $3^{*}$ and has been followed for 8 weeks, the filtering bleb has remained Seidel negative with an IOP of $17 \mathrm{mmHg}$.

\section{Case 5}

A 78-year-old woman with primary open angle glaucoma (POAG) presented with a bleb leak 25 months after trabeculectomy with $\mathrm{MMC}$ in left eye. At examination, she had deep anterior chamber (AC), an IOP of $8 \mathrm{mmHg}$, and best corrected visual acuity (VA) of 20/60. Conjunctival patch grafting was performed. On postoperative day 1 the bleb was still Seidel positive. However at 4 weeks and 4 days of follow-up the bleb was Seidel negative and the conjunctival graft appeared secure and well healed. The patient has been followed for 30 weeks and the filtering bleb remained Seidel negative, however IOP was maintained at $8 \mathrm{mmHg}$.

\footnotetext{
" Illustrations are not in increasing order of appearance in the text because the postoperative progressive resolution of the bleb leak is the main purpose of these pictures.
} 


\section{Case 6}

An 81-year-old woman with primary open angle glaucoma (POAG) presented bleb leak 28 months after trabeculectomy without antimetabolite in right eye. Cryotherapy was performed 5 times an in attempt to stop the bleb leak, but was unsuccessful. One month after cryotherapy was performed, it was decided to proceed with a free conjunctival patch graft. At examination the patient had deep anterior chamber (AC), an IOP of $10 \mathrm{mmHg}$, and best corrected visual acuity of 20/40. Conjunctival patch grafting was performed. On postoperative day 1 the bleb was Seidel negative. The patient has been followed for 22 weeks, the bleb remained Seidel negative and IOP was $15 \mathrm{mmHg}$.

\section{Case 7}

A 53-year-old woman with primary open angle glaucoma (POAG) presented with a bleb leak 24 months after trabeculectomy with 5-FU in left eye (Figure1). At examination, she had

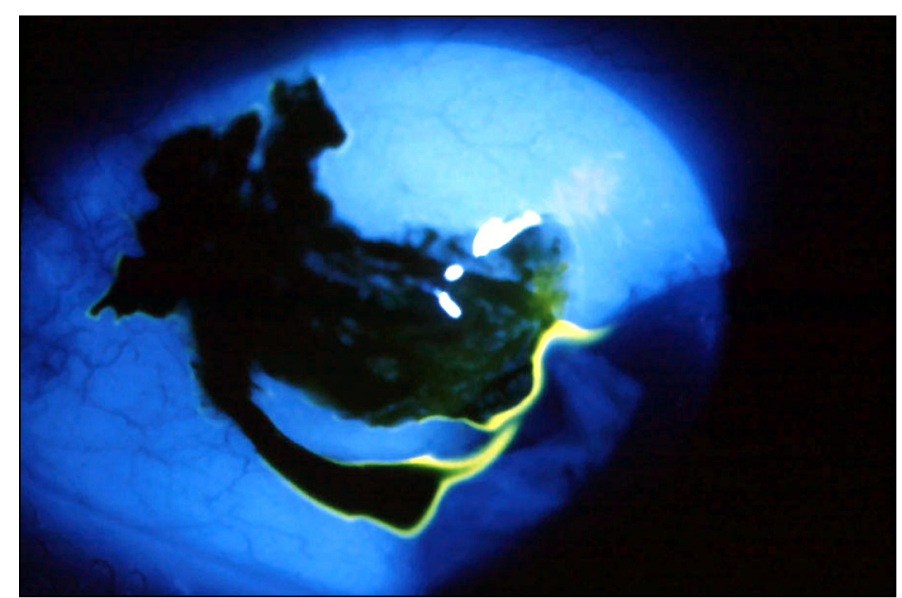

Figure 1 - Slit lamp pre-operative photograph of a bleb leak (Seidel positive) of the patient described as case 7

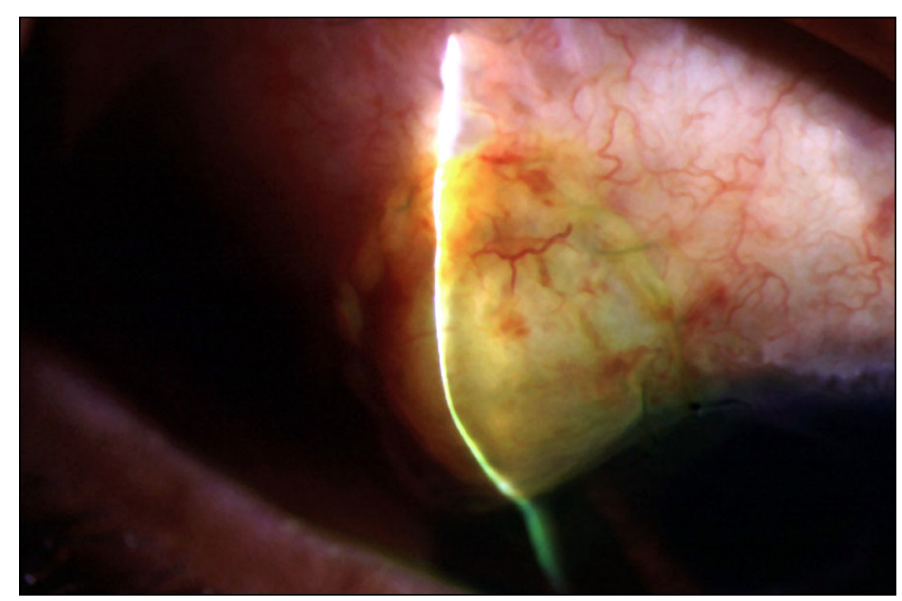

Figure 2 - Slit lamp photograph of the same patient, now with a free conjunctival graft one day postoperatively. deep anterior chamber (AC), an IOP of $5 \mathrm{mmHg}$, and best corrected visual acuity of 20/70. Conjunctival patch grafting was performed. On postoperative day 1 bleb was Seidel negative (Figure 2). She continued to do well on the following visits and the appearance at one month postoperatively is shown in Figure 4 . This patient has been followed for 34 weeks, the bleb remained Seidel negative and IOP was maintained at $10 \mathrm{mmHg}$.



Figure 3 - Slit lamp photograph of a free conjunctival graft considered a complete success, two weeks postoperatively (case 4)

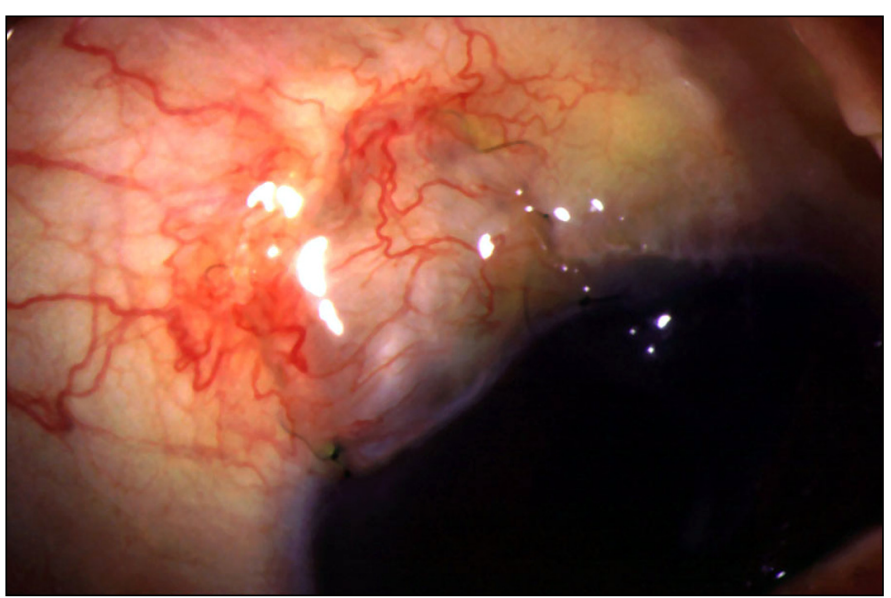

Figure 4 - Slit lamp photograph of a free conjunctival graft one month postoperatively (case 7 )

\section{RESULTS}

With an average follow-up of 7 months, conjunctival patch grafting stopped filtering bleb leak within 1 week in 3 eyes (cases 4, 6 and 7) and within 1 month in 1 eye (case 1). Bleb leak stopped after 1 month in 2 eyes (cases 2 and 5) and did not stop in one other eye (case 3). An IOP greater than $7 \mathrm{mmHg}$ was maintained in 5 patients $(71.4 \%)$, satisfactory anterior chamber depth was maintained in all patients, and pretreatment vision was preserved in 5 patients $(71.4 \%)$ (Tab. 1, 2). 


\begin{tabular}{|lcc|}
\hline \multicolumn{2}{|c|}{ Table 1. Patient characteristics and follow-up } \\
Study variable & Mean & SD \\
Age (years) & 64 & 16 \\
Preop IOP (mmHg) & 7 & 3 \\
$\begin{array}{l}\text { Follow-up until Seidel } \\
\text { negative (days) }\end{array}$ & 39 & 57 \\
$\begin{array}{l}\text { Total follow-up (weeks) } \\
\text { SD = Standart deviation }\end{array}$ & 28 & \\
\hline
\end{tabular}

\begin{tabular}{|lcc|}
\hline \multicolumn{2}{|c|}{ Table 2. Surgical results } \\
Postop outcome & N. patients & $\%$ \\
Seidel test at last follow-up & & \\
$\quad$ Positive & 1 & 14.2 \\
Negative & 6 & 85.8 \\
Total & 7 & 100 \\
Results & & \\
Complete success & 3 & 42.8 \\
Partial success & 2 & 28.6 \\
Failure & 2 & 28.6 \\
Total & 7 & 100 \\
\hline
\end{tabular}

\section{DISCUSSION}

Bleb leaks can occur months to years after filtration surgery $^{(5-7)}$. Their recognition, often presented by increased tearing, marked hypotony and a positive leak demonstrated by $2 \%$ fluorescein, is very important in glaucoma management ${ }^{(8)}$. Ischemic, thin-walled blebs are more likely to develop after full-thickness filtration surgeries ${ }^{(6-8)}$ or trabeculectomies with adjunctive use of antimetabolities ${ }^{(1-4,8,10)}$, particulary mitomycin $\mathrm{C}^{(17)}$, and are also more susceptible to rupture and present late leakage than thicker blebs ${ }^{(1-2,6-7)}$. Antimetabolites have been shown to contribute to leaks that may come from different sites and different times and are associated with conjunctival epithelial breakdown and stromal degeneration $^{(18)}$. Lamping et al. reported an incidence of $3.3 \%$ of late blebs leaks among full-thickness procedures ${ }^{(7)}$. Chronic blebs leaks may predispose to endophthalmitis, hypotony, flat anterior chamber, hypotony maculopaty, peripheral anterior synechiae and choroidal detachment ${ }^{(4,10,14)}$. Medical and surgical alternatives have been described to treat bleb leaks. Typical$1 y$, initial treatment is aqueous suppression, prophylactic antibiotics and observation. However, this is an inadequate longterm solution because although these leaks spontaneously resolve, recurrence may happen ${ }^{(4)}$. Successful closure of bleb leaks often requires a surgical revision ${ }^{(8)}$. Surgical bleb revision has a high success rate of closing late bleb leaks ${ }^{(8)}$. Free conjunctival grafting has been described as a less invasive surgical alternative for the treatment of leaking blebs. Wilson and Kotas-Neumann have found that free conjunctival grafting was effective in stopping bleb leaks and maintaining functioning blebs in 4 eyes of 4 patients with a minimum follow-up of two months ${ }^{(19)}$. In our study, with a mean follow- up of 7 months, bleb leakage stopped within 1 month in 4 eyes, and after 1 month in 2 eyes ( 4.5 weeks and 10 weeks). Its uncertain wether conjunctival patch grafting had any indirect role in the eventual closure of bleb leaks in these 2 eyes. In one eye bleb leak persisted. Pretreatment vision and appropriate IOP control was maintained in the majority of patients and satisfactory anterior chamber depth was present in all patients.

\section{CONGLUSIONS}

Free conjunctival patch grafting seemed to be a safe and effective method of stopping bleb leaks in this group of patients, thereby reducing the risk of infection and maculopathy secundary to hypotony, maintaining glaucoma control and preserving vision with few postoperative complications. Future prospective randomized and case-control clinical studies will be necessary to determine the role of free conjunctival grafts in the treatment of leaking blebs.

\section{RESUMO}

Objetivo: Avaliar a eficácia dos enxertos de conjuntiva no tratamento de bolhas filtrantes com vazamento após trabeculectomia. Métodos: Estudo retrospectivo de sete pacientes com bolhas filtrantes vazando que foram reparadas com enxertos de conjuntiva. Foi avaliada a eficácia deste procedimento em controlar o vazamento, manter pressão intra-ocular (PIO) satisfatória, manter profundidade satisfatória da câmara anterior, e preservar acuidade visual. Resultados: Enxertos de conjuntiva aparentemente pararam o vazamento em 6 pacientes $(85.7 \%)$, mantiveram PIO satisfatória em 5 pacientes (71.4\%), mantiveram profundidade satisfatória da câmara anterior em todos os pacientes $(n=7)$, e preservaram acuidade visual semelhante à antes do tratamento em 3 pacientes. Conclusões: $O$ uso de enxertos de conjuntiva parece ser método efetivo para tratar bolhas filtrantes com vazamento, sem perder o controle da PIO.

Descritores: Glaucoma; Trabeculectomia, Conjuntiva/cirurgia; Conjuntiva/transplante

\section{REFERENCES}

1. Khaw PT, Doyle JW, Sherwood MB, Smith MF, McGorray S. Effects of intraoperative 5-fluorouracil or mitomycin $\mathrm{C}$ on glaucoma filtration surgery in the rabbit. Ophthalmology 1993;100:367-72.

2. Ticho U, Ophir A. Late complications after glaucoma filtering surgery with adjunctive 5-fluorouracil. Am J Ophthalmol 1993;115:506-10.

3. Three-year follow-up of the Fluorouracil Filtering Surgery Study. Am J Ophthalmol 1993;115:82-92.

4. Harris LD, Yang G, Feldman RM, Fellman RL, Starita RJ, Lynn J, Chuang AZ. Autologous conjunctival resurfacing of leaking filtering blebs. Ophthalmology 2000;107:1675-80.

5. Sugar HS. Complications, repair and reoperation of antiglaucoma filtering blebs Am J Ophthalmol 1967;63:825-33. 
6. Blondeau P, Phelps CD. Trabeculectomy vs. Thermosclerostomy. A randomized prospective clinical trial. Arch Ophthalmol, 1981;99:810-6.

7. Lamping KA, Bellows AR, Hutchinson BT, Afran SI. Long-term evaluation of initial filtration surgery. Ophthalmology 1986;93:91-101.

8. Wadhwani RA, Bellows AR, Hutchinson BT. Surgical repair of leaking filtering blebs. Ophthalmology 2000;107:1681-7.

9. Pederson JE. Ocular hypotony. In: Ritch R, Shields MB, Krupin T, editors. The glaucomas. St. Louis: Mosby; 1989.

10. Blok MD, Kok JH, van Mil C, Greve EL, Kijlstra A. Use of the Megasoft Bandage Lens for treatment of complications after trabeculectomy. Am J Ophthalmol 1990;110;264-8.

11. Grady FJ, Forbes M. Tissue adhesive for repair of conjunctival buttonhole in glaucoma surgery. Am J Ophthalmol 1969;68:656-8.

12. Hennis HL, Stewart WC. Use of the argon laser to close filtering bleb leaks. Graefes Arch Clin Exp Ophthalmol 1992;230:537-41.
13. Geyer O. Management of large, leaking, and inadvertent filtering blebs with the neodymium:YAG laser. Ophthalmology 1998;105:983-7.

14. La Borwit SE, Quigley HA, Jampel HD. Bleb reduction and bleb repair after trabeculectomy. Ophthalmology 2000;107:712-8.

15. Kosmin AS, Wishart PK. A full-thickness scleral graft for the surgical management of a late filtration bleb leak. Ophthalmic Surg Lasers 1997;28:461-8.

16. Smith MF, Magauran RG, Betchkal J, Doyle JW. Treatment of postfiltration bleb leaks with autologous blood. Ophthalmology 1995;102:868-71.

17. Greenfield DS, Liebmann JM, Jee J, Ritch R. Late onset bleb leaks after glaucoma filtering surgery. Arch Ophthalmol 1998;116:443-7.

18. Belyea DA, Dan JA, Stamper RL, Lieberman MF, Spencer WH. Late onset of sequential multifocal bleb leaks after glaucoma filtration surgery with 5fluorouracil and mitomycin C. Am J Ophthalmol 1997;124:40-5.

19. Wilson MR, Kotas-Newmam R. Free conjunctival patch for repair of persistent late bleb leak. Am J Ophthalmol 1994;117:569-74.

\section{SIMAsp Simpósio internacional Moacyr Álvaro}

\section{2 a 14 de fevereiro de 2.004 \\ São Paulo - SP}

Promoção: Centro de Estudos Oftalmológicos Moacyr E. Álvaro - UNIFESP INFORMA C̣ÕES: Tel.: (11) 5575-4243 E-mail: ceo@oftalmo.epm.br 